\title{
EL LIVRO DE ALVEITARIA DEL CÓD. 2294 DE LA BIBLIOTECA NACIONAL DE PORTUGAL: ANOTACIONES PARA SU HISTORIA Y DESCRIPCIÓN*
}

\author{
Gerardo PÉREZ BARCALA \\ gerardop@ucm.es \\ Universidad Complutense de Madrid
}

\section{INTRODUCCIÓN}

Sin pretender ahondar en los pormenores de un asunto tan interesante y estudiado como el de la fundación e historia de la Biblioteca Nacional de Portugal, reparar en algunos de ellos se hace necesario cuando se trata de indagar en cuestiones relativas a los fondos que custodia, tanto para seguir los principales pasos de su "vida" en el centro como para reconstruir etapas anteriores de la misma. Como es bien conocido, la más importante institución bibliográfica de Portugal fue fundada, con el nombre de Real Biblioteca Pública da Corte, por la reina D. Maria I el 29 de febrero de 1796, tuvo como primer bibliotecário-mor a António Ribeiro dos Santos y se ubicó en el ala oeste del Terreiro do Paço de la neurálgica Praça do Comércio lisboeta. Rebautizada como Biblioteca Nacional de Lisboa desde 1837 y transferida al Convento de São Francisco, el enriquecimiento de sus fondos determinó que desde 1969 la sede se trasladase al actual edificio de la avenida del Campo Grande'

\footnotetext{
* Este trabajo es fruto de las investigaciones realizadas en el proyecto Edición criticointerpretativa do Livro d'Alveitaria. Bases para unha plataforma on-line da tradición do De medicina equorum, desarrollado en el marco de la Modalidade B del «Programa de formación inicial da etapa posdoutoral» del Plan I2C de la Xunta de Galicia. Por su amabilidad y disponibilidad, estoy en deuda con todo el personal de la Sala de Reservados de la BNP, así como con los profesores João José Alves Dias e Isabel Vilares Cepeda, con quienes en aquel centro entablamos fructíferas y enriquecedoras conversaciones. Asimismo, no quiero dejar de expresar mi gratitud a Márcia Carolina Ferreira Oliveira y Francisco António Lourenço Vaz, por regalarme su saber sobre Cenáculo, y a Ricardo Pichel, por su impagable disposición ante cualquier cuestión paleográfica o codicológica. Aunque los errores o imprecisiones que pueda haber en este artículo sean responsabilidad única de quien escribe, sin la ayuda de todos ellos este trabajo sería algo bien distinto.

${ }^{1}$ Sobre la génesis de la BNP y sus diferentes pasos (lugares en los que tuvo su sede, procedencia de sus fondos, estructura corporativa y reorganización) existe tan nutrida y completa bibliografía que sería imposible abarcarla por completo. Nos permitimos mencionar por su visión panorámica uno de tantos trabajos que Manuela D. Domingos dedicó al argumento: Manuela D. Domingos, Biblioteca Nacional. Crónica de 200 anos, Lisboa, Inapa, 1992 (Separata de Tesouros da Biblioteca Nacional). Un sucinto repaso por la historia de la institución y la procedencia de sus fondos medievales puede verse en Isabel Vilares Cepeda y Manuela
} 
En una pared a la entrada de la BNP puede verse un mural confeccionado en 2006 como homenagem de la institución aos seus doadores e mecenas del século XVIII y, entre las personalidades homenajeadas, figura el nombre de Frei Manuel do Cenáculo. En efecto, en sus inicios, el centro se alimentó en buena medida de donaciones particulares y una de las figuras que más contribuyó a ello fue Manuel do Cenáculo Villas Boas (1724-1814)². Este personaje había alentado la fundación de la biblioteca como institución pública desde los tiempos en que, en el marco de las reformas culturales emprendidas por el Marqués do Pombal en la segunda mitad del siglo XVIII, había sido diputado y presidente de la Real Mesa Censória, organismo que, como se sabe, constituyó el germen de la Real Biblioteca Pública da Corte. Por no hablar de las piezas numismáticas, los estantes de esta institución se enriquecieron con un nutrido número de ejemplares (manuscritos e impresos) que el insigne erudito donó entre 1796 y 1798 a la Real Biblioteca Pública da Corte que acababa de ser fundada, en un deseo de estimular la erudición que llevó también al insaciable bibliófilo a ofrecer varios volúmenes a la biblioteca del convento de Nossa Senhora de Jesus en Lisboa (la actual Academia Real das Ciências) o a fundar bibliotecas públicas como la de Évora, entre otras ${ }^{3}$.

D. Domingos, «Biblioteca Nacional», en Giulia Lanciani y Giuseppe Tavani (orgs. y coords.), Dicionário da Literatura Medieval Galega e Portuguesa, Lisboa, Caminho, 1993, pp. 97-99, así como en Literatura Hispânica da Idade Média na Biblioteca Nacional. Catálogo da Exposição realizada por ocasião do IV Congreso da Associação Hispânica de Literatura Medieval, Lisboa, Biblioteca Nacional-Edições Cosmos, 1991, pp. 9-10.

${ }^{2}$ Ciertamente, en sus comienzos la Biblioteca se nutrió de donaciones que procedían, sobre todo, de la Real Mesa Censória, de la Casa dos Clérigos Regulares da Divina Providência (Teatinos) y de los fondos de Cenáculo. Importante documento es, en este sentido, el Resumo da Constituição e Estado da Biblioteca de Lisboa, de Ribeiro dos Santos (BNP, CÓD. 4677). Además de información relativa a la organización y funcionamiento del centro, ese texto ofrece detalles sobre la distribución de los ejemplares e informa de la procedencia de los fondos: las donaciones de Cenáculo habrían contribuido a enriquecer las diez salas de libros impresos, la de manuscritos y la de antigüedades, esto es, las tres grandes secciones en las que Ribeiro dos Santos organizó la Real Biblioteca Pública da Corte (cfr. infra n. 7). El Resumo ha sido publicado por Luís Fernando de Carvalho Dias, «O primeiro regulamento da Biblioteca Nacional», Revista da Biblioteca Nacional, 1/1 (1981), pp. 174-183.

${ }^{3}$ Sobre la fundación de la BNP, su «derivación» de la Biblioteca de la Real Mesa Censória y los primeros tiempos de la institución, así como sobre el papel desempeñado por Cenáculo en la fundación de bibliotecas públicas (la Nacional entre otras), su relación con algunos eruditos de la época (Ribeiro dos Santos entre ellos), su interés por la bibliofilia y los ejemplares que donó a la Real Biblioteca Pública da Corte y otros organismos, la bibliografía es amplísima: cfr., entre otros, Raúl Proença, «Antecedentes e origens da Biblioteca Nacional de Lisboa», Anais das Bibliotecas e Arquivos, 7/11 (1922), pp. 154-165; Manuela D. Domingos, «Para a história da Biblioteca da Real Mesa Censória», Revista da Biblioteca Nacional, S.2, 7/1 (1992), pp. 137-158; Ead., «A Primeira Biblioteca Pública Portuguesa, 1775-1795. Planos, Projectos e Primeiros Fundos», Cadernos BAD, 1 (1994), pp. 59-70; Ead. (coord.), «Casa dos Livros de Beja»: doação de Frei Manuel do Cenáculo à Real Biblioteca Pública da Corte, Lisboa, Biblioteca Nacional, 2006; Ead., «Frei Manuel do Cenáculo no panorama intelectual de Setecentos: o erudito e o mecenas», Revista Convergência Lusiada, 24 (2007), pp. 42-66; Francisco António Lourenço Vaz, «A ideia de biblioteca na obra de D. Frei Manuel do Cenáculo», en Filipa Medeiros (ed.), Acervos Patrimoniais: novas perspectivas e abordagens, Mértola, 
Además de los apuntes ofrecidos por Ribeiro dos Santos en el Resumo da Constituição e Estado da Biblioteca de Lisboa (cfr. n. 2), sobre la importancia de los donativos de Cenáculo a la BNP proporciona rica información la correspondencia que entre 1796 y 1808 intercambiaron el obispo de Beja y el primer director del centro. Las misivas entre ambos personajes permiten reconstruir uno de los episodios más interesantes de la historia bibliográfica y cultural de Portugal: las donaciones de Cenáculo a la Real Biblioteca Pública da Corte alcanzan tales proporciones que António Ribeiro dos Santos no escatima en elogios hacia quien tanto contribuyó a dar esplendor y enriquecimiento a la institución con sus tesoros ${ }^{4}$. El Catalogo Methodico dos livros que o Ex ${ }^{m o}$. e R $R^{m o}$. D. Fr. Manoel do Cenaculo Villas-boas, Bispo de Beja, Doou à Real Bibliotheca Publica da Corte No Anno de 1797 está introducido por una carta autógrafa de Cenáculo, fechada en Beja el 24 de marzo de 1797 y dirigida al príncipe D. João VI (hijo de la reina D. Maria I), en la que ruega que se acepte su donación:

Rogo eu Bispo de Beja humildemente seja servido aceitar a livre doação, que faço à Real Biblioteca Pública de Lisboa pelo seu inspirado estabelecimento eu [sic] utilidade, e crédito nacional, dos livros, em que me pareceu haver dignidade, raridade, e de alguma proporção, os quais separei daqueles, que para os estudos próprios desta diocese nela se devem conservar, não havendo nesta dilatadíssima província livraria alguma pública, sendo necessária a cada instante: assim como também compreendo na mesma doação, pelo meu amor pátrio o monetário de mais de três mil medalhas não duplicadas, de cobre, prata, e oiro, em que há raríssimas, algumas desconhecidas, e gregas, e outras raridades dignas do Museu Real, e Público, pois que o ânimo do Bom, e Augusto Príncipe não é

Campo Arqueólogico de Mértola, 2012, pp. 77-96; Francisco António Lourenço Vaz y José António Calixto (coords.), Frei Manuel do Cenáculo constructor de bibliotecas, Casal de Cambra, Caleidoscópio, 2006; Márcia Carolina Ferreira de Oliveira, A bibliofilia em Portugal no início da época contemporânea. O exemplo de Frei Manuel do Cenáculo, Évora, Universidade de Évora, tese de doutoramento, 2012, 2 vols.; Maria Luísa Rosendo Cabral, Património bibliográfico e bibliotecas na construção da identidade colectiva. Entre um conceito e o seu desenvolvimento, 1750-1800, Lisboa, Universidade Nova de Lisboa-Faculdade de Ciências Sociais e Humanas, tese de doutoramento, 2013, 2 vols. En particular, para los intereses de Cenáculo por las piezas arqueológicas, vid. Rui Morais, «Um caso exemplar: Cenáculo e o coleccionismo no Portugal de Setecentos», Cadmo, 19 (2009), pp. 209-228.

${ }^{4}$ Hasta tal punto es así que, en una carta fechada el 20 de enero de 1797, el bibliotecáriomor declara haber «recolhido, e distribuído» la «livraria» de Cenáculo «por suas classes em uma sala especialmente destinada para ela, que havemos consagrado com o respeitável titulo de Biblioteca de V. Ex», y, en otra del 24 de marzo de ese mismo año, refiere que, abiertas las puertas del centro, «o sagrado nome de seu ilustre benfeitor tem conciliado de tal modo a atenção dos concorrentes, que todos vão com alvoroço à Casa dos Livros de Beja, como em romagem ao santuário das musas». Véase la reproducción de las misivas relacionadas con este asunto y su oportuno marco interpretativo en Rosendo Cabral, Património bibliográfico e bibliotecas, op. cit., vol. I, pp. 216-254, y vol. II (Anexos), pp. 160-248 (Anexo II, «Epistolografia em torno da doação de Cenáculo»). 
para menos do que repetir em sua felicíssima Corte o Museu de Alexandria ${ }^{5}$.

\section{El CÓD. 2294, LAS DONACIONES DE CENÁCUlO Y LOS PRIMEROS CATÁLOGOS}

En el tercero de los volúmenes de aquel registro, titulado concretamente Catalogo dos Mss. da Doação do Bispo de Beja, se recogen, ordenados por materias, los diferentes libros que Cenáculo cede a la institución. Para el arte de alveitaria tan solo consta en el elenco una obra, identificada como Livro de Alveitaria $(=L A)$ y descrita con una sintética indicación «Fol. vol.» (fol. 36r) ${ }^{6}$ en probable referencia al formato del ejemplar. La imprecisa alusión se hace más concreta gracias a la información que arroja el documento al que Ribeiro dos Santos asigna el título de Copia Do Catalogo de Livros que o Ex $x^{\text {mo }}$ e Rev ${ }^{m o}$ Bispo de Beja pertende remeter para a Real Bibl[i]otheca Publica da Corte: en el fol. 9r se menciona un manuscrito de alveitaria del que se dan breves pinceladas como «do tempo d'El Rey D. Dinis», «letra de então», «inedito» $\mathrm{y} \ll$ fol.» ${ }^{7}$.

${ }^{5}$ Catalogo Methodico dos Livros que o $\mathrm{Ex}^{\mathrm{mo}}$. e $\mathrm{R}^{m o}$. D. Fr. Manoel do Cenaculo Villasboas, Bispo de Beja, Doou à Real Bibliotheca Publica da Corte No Anno de 1797, 4 vols., CÓD. 11522-11525. El vol. I está digitalizado en $<$ http://purl.pt/6382/4>. La carta del citado Catalogo (vol. I, fols. 3-4) se cita a partir de la transcripción de Rosendo Cabral, Património bibliográfico e bibliotecas, op. cit., vol. II (Anexos), p. 180.

${ }^{6}$ Este volumen III del Catalogo es el CÓD. 11525 de la BNP y está digitalizado en: $<$ http:// purl.pt/5944/2>.

${ }^{7}$ Copia Do Catalogo de Livros que o Ex $x^{m o}$ e Rev ${ }^{m o}$ Bispo de Beja pertende remeter para a Real Bibl[i]otheca Publica da Corte, BNP, CÓD. 11524, digitalizado en <http://purl. pt/24964/4>. Es responsabilidad de Ribeiro dos Santos la elaboración de un importante número de catálogos bibliográficos. Algunos, como los mencionados o como los listados autógrafos de los códices 4630 y 4631, dan cuenta de ejemplares que era de interés adquirir. En otros se ofrecen las referencias de volúmenes de la Biblioteca correspondientes a diferentes materias (botánica, nobiliarios, libros de viajes, etc.). Otros tienen que ver con la organización metódica (sistemática) que el bibliotecário-mor había hecho del material bibliográfico en los primeros tiempos de la Biblioteca. Particularmente significativos en esta última dirección son el CÓD. 4716, con un «Plano Para $<\mathrm{Da}>$ a Distribuição Methódica Dos Livros da Historia Literaria» (fol. 105r) que contiene indicaciones sobre la organización de bibliotecas, o el CÓD. 4683, en el que se incluyen unos «Planos de Distribuição Methódica para certas clases de Livros pelo $\mathrm{D}^{\text {or }}$ Antonio Ribeiro» (fol. 120r), una «Distribuição Methódica para se arranjarem os livros e Tratados de diversas classes na Real Biblioteca de Lisboa pelo $\mathrm{D}^{\text {or }}$ Antonio Ribeiro. Aqui estão somente algũas folhas que se hião tirando a tempo para formarem depois o sistema geral da arrumação» (fol. 149r) y una «Noticia da Distribuição Methódica de todos os Livros, Mss. e Peças da Real Biblioteca da Corte» (fol. 168r): según las indicaciones aquí ofrecidas, el material bibliográfico se disponía temáticamente por salas (con secciones y subsecciones)-Salas I y II: Historia, Sala III: Bellas Letras, Sala Iv: Sciencias Naturaes, etc.- en las que había estantes ('estanterías'), casas ('estantes') y volumes; a los Manuscriptos, distribuidos en seis clases (Historia, Bellas Letras, Sciencias Naturaes e Philosophicas, Sciencias Civis e Politicas, Sciencias Ecclesiasticas y Polygraphia ou Varia Erudição), estaba destinada la Sala XI, mientras que la Sala XII custodiaba Antiguidades organizadas también en seis clases-Colleção Numismatica, Peças de Statuaria, Esculptura e Gravadura, Peças de Estamparia, Peças de Pintura, Peças Varias de outras Artes, Cartas, Mappas e Plantas-. Análoga información sobre la distribución de las salas de la Biblioteca ofrece el citado Resumo da Constituição e Estado 
Tras las breves alusiones bibliográficas del Catalogo y de la Copia ha de verse una referencia al volumen inventariado actualmente en la BNP con la signatura CÓD. 2294. Este se abre, en efecto, con un texto presentado con el título «Liuro d'alueitaria pera quallquer besta que qujseres» (fol. 1r) ${ }^{8}$, al que, según informan el prólogo y el explicit, puso fin en 1318 el Mestre Giraldo precisamente por encargo de don Denis:

\section{[prólogo]}

o muy nobre Senhor rrey dom donjs mandou a mym meestre giraldo que conposesse $\mathrm{E}$ hordenasse hũu liuro ho mjlhor que a mym semelhasse em que compillasse hordenadamente todallas Coussas que ssom contheudas em cada hũu destes liuros desusso dictos ./ [...] E este liuro he partjdo em duas partes .// A prjmeira he das coussas que conuee $m$ ao cauallo do tenpo em que naçe ataa o tenpo que lhe deyta $m$ freo E sella .// A segunda he de todallas enfermjdades que podem acaecer aos cauallos da cabeça ataa os pees [...] .// E este liuro contem per todo esto sateenta E sete capitollos (fol. 1r, lín. 13-28).

\section{[explicit $]$}

Aqui se acaba hũu liuro de aluejtarja que treladou $e$ hordenou meestre giraldo fisico do nobre Senhor rrey dom donjs per seu mandado na cjdade de lixboa na era da encarnaçom de Jhsu Cristo mjll iij. ${ }^{\circ}$ xviij. ${ }^{\circ}$ (1318) anos (fol. 43v, lín. 24-26 - fol. 44r, lín. 1-3).

A la identificación del CÓD. 2294 con el $L A$ donado por Cenáculo en la etapa fundacional de la BNP contribuyen también algunas señales que ponen de manifiesto la presencia del ejemplar en el centro desde sus inicios. Por un lado, en el códice confluyen varias signaturas que dan cuenta de la medida en que participó en las trasformaciones realizadas en la organización y catalogación de los fondos bibliográficos de la Biblioteca. Sin pretender un análisis exhaustivo de una

da Biblioteca de Lisboa (BNP, CÓD. 4677): cfr. Dias, «O primeiro regulamento», art. cit., pp. 178-180. Sobre los catálogos de Ribeiro dos Santos, cfr. Rosendo Cabral, Património bibliográfico e bibliotecas, op. cit., vol. I, pp. 328-350.

${ }^{8}$ La obra fue transcrita por Gabriel Pereira, «Livro d'Alveitaria do Mestre Giraldo», Revista Lusitana, 12/1-2 (1909), pp. 1-60. Este trabajo fue reproducido posteriormente por Cacilda de Oliveira Camargo, Carlos Alberto Iannone y Jorge Cury (Textos medievais portugueses. Livro de Alveitaria de Mestre Giraldo, Araraquara, Universidade Estadual Paulista «Julio de Mesquita Filho»-Instituto de Letras, Ciencias Sociais e Educação-Centro de Estudos Portugueses «Jorge de Sena», 1988, 2 vols.), que añaden una paráfrasis al portugués moderno con anotaciones. No obstante, las citas se ofrecen a partir de la transcripción del texto que hemos preparado (consignando el folio y la(s) línea(s) del manuscrito), interviniendo en la unión y separación de palabras y en el desarrollo de las abreviaturas, como fase previa para la elaboración de una edición interpretativa que estamos elaborando con el objeto de subsanar algunas de las deficiencias del meritorio, aunque insuficiente, trabajo de Pereira. Las citas del prólogo y del explicit que se dan más abajo se encuentran en la reproducción de Pereira, "Livro d'Alveitaria», ed. cit., pp. 2 y 59, respectivamente. 
cuestión sobre la que reconocemos nuestras limitaciones y partiendo de información facilitada amabilísimamente por la profesora Isabel Vilares Cepeda, ha de señalarse que la actual signatura, CÓD. 2294, es relativamente moderna y puede remontarse a los años 60 del siglo xx: al parecer, antes de que la Biblioteca se mudase a su actual emplazamiento y siendo su director, entre 1951 y 1974, Manuel Santos Estevens, se fijó un sistema de catalogación de los manuscritos que consistía en anteponer la abreviatura CÓD. a la simple referencia numérica con la que aquellos se identificaban anteriormente, encargándose de ejecutar las directrices de Estevens en los ejemplares algún funcionario del centro. Este habría sido probablemente quien apuntó a lápiz en los folios inicial (fol. 1r, margen superior izquierdo) y final (fol. 60v, margen inferior izquierdo) la actual signatura, «CÓD. 2294», que reemplaza a la previa, «2294». Esta última, escrita en tinta azul en la parte superior izquierda de la guarda inicial, sustituye a su vez a otra anterior a lápiz, «FG 2294», que, aunque borrada, puede adivinarse sin dificultad y que es consecuencia de una reorganización de los ejemplares por secciones (correspondiendo $F G$ a la llamada Fundo geral [de manuscritos]) que podría datar de la segunda mitad del siglo XIX, de los tiempos en que António Enes fue director del centro (cfr. n. 24). El volumen tuvo, además, otra signatura anterior, H-5-39, que debió de ser la primitiva y que debe de remontar, por tanto, a los tiempos de Ribeiro dos Santos. Aunque nada dice el ya mencionado Resumo da Constituição e Estado da Biblioteca de Lisboa sobre el sistema de catalogación de los manuscritos, la referida signatura revela que para ellos debía de utilizarse el mismo método que para los libros impresos, distribuidos en las estanterías de las salas del siguiente modo:

As estantes ['estanterías'] estão todas numeradas e marcadas e dentro delas o estão também os Livros, tendo cada um deles na lombada bilhete ['signatura'] com tres notas que indicão a estante, a que pertence, a Casa ['estante, balda'] e o lugar que nela tem entre os outros libros; e também com estas notas estão todos eles lançados em seus catálogos respectivos assim para por elas se procurarem quando convier?.

Para ayudar a la identificación de un ejemplar que modificó su signatura en el centro, la referencia alfanumérica consta en un documento de uso interno en la Biblioteca ${ }^{10}$, así como en una sobria ficha

${ }^{9}$ Cfr. Dias, «O primeiro regulamento», art. cit., p. 179. Así pues, en la etapa inicial de la Biblioteca en el Terreiro do Paço, el códice estaría en la sala XI, destinada a custodiar los manuscritos, como indica el mismo documento de Ribeiro dos Santos. En dicho espacio se ubicaría concretamente en la balda 5 de la estantería identificada como $\mathrm{H}$, correspondiendo al ejemplar el no 39 .

${ }^{10} \mathrm{Se}$ trata del volumen titulado Fundo geral de manuscritos. Equivalências, donde se indica (p. 79) que el actual CÓD. 2294 era primitivamente identificado como H-5-39. 
en papel ${ }^{11}$ y en las referencias en línea del catálogo de la BNP y de BITAGAP (manid 1044) ${ }^{12}$.

Redunda también en la presencia del volumen en la institución desde los primeros tiempos el análisis de la cronología de los cuños con los que, en fases sucesivas, la BNP dejó constancia de que el ejemplar era de su propiedad. El más reciente de los estampados en él es el redondeado de color rojo que, con el lema Biblioteca Nacional de Lisboa, se imprime en el margen inferior de los fols. 25r y 50r y que empieza a utilizarse a partir de 1922 en la época en que era director del centro Jaime Cortesão. En el margen inferior de los fols. 2r, 17r, 49r, 59v, 60r, en el derecho del fol. 5r y en el izquierdo del fol. $60 \mathrm{v}$, asoma otro cuño de color negro y forma más ovalada que, con el símbolo de la corona y con el mismo nombre de la institución, fue empleado con anterioridad, concretamente desde 1836, en los tiempos en que la dirección fue asumida por Vasco Pinto de Balsemão. Pero en el margen superior derecho del folio inicial del códice puede verse el que, también en color negro, con la corona y con forma ovalada, fue el cuño utilizado en el momento de la fundación del organismo en $1796^{13}$.

La primitiva signatura y el primer cuño aseguran que el CÓD. 2294 se encuentra en la BNP desde los orígenes de la institución y que, por lo tanto, ese es el $L A$ donado por Cenáculo al que se refieren los catálogos antes mencionados. Nada dicen estos sobre cómo llegó a manos del erudito un códice que, a pesar de sus reducidas dimensiones y de la sobriedad de su elaboración, posee un valor incalculable al conservar la única copia conocida del primer tratado de veterinaria escrito en portugués. Para explicar tal particular basta con rememorar el espíritu coleccionista y el afán bibliófilo que, en el marco de las corrientes del iluminismo del momento, se convirtieron en señas indiscutibles de la personalidad de Cenáculo y que lo llevaron a estrechar contactos con libreros y otros personajes imbuidos de análogas inquietudes.

\footnotetext{
${ }^{11}$ En este documento, conservado en los antiguos ficheros en papel de la Sala de Reservados, al CÓD. 2294 se le asigna también la referencia H-5-39 y se reduce su descripción a estos detalles: «Livro <que trata> de alveitaria. Fol. vol. 1. Caracter antigo».

12 Para el primero, cfr. <http://porbase.bnportugal.pt/ipac20/ipac.jsp?session=10175 744R4667.866812\&profile = porbase \&uri=full\%3D3100024 !1363257 !0\&booklistform at=>. Para el enlace a BITAGAP, cfr. $<$ http://pb.lib.berkeley.edu/xtf/servlet/org.cdlib.xtf.dynaXML.DynaXML? source=BITAGAP/Display/1044BITAGAP.MsEd.xml\&style=MsEd x s $1 \% 0 \mathrm{~A} \% 0 \mathrm{~A} \% 20 \% 0 \mathrm{~A} \% 20 \% 0 \mathrm{~A} \% 20 \&$ gobk=http $\% 3 \mathrm{~A} \% 2 \mathrm{~F} \% 2 \mathrm{Fpb} .1 \mathrm{lib}$.berkeley. edu $\% 2$ Fxtf $\% 2$ Fservlet $\% 2$ Forg.cdlib.xtf.crossQuery.CrossQuery $\% 3$ Frmode $\% 3$ Dphilo $\% 26 \mathrm{mst}$ ype $\% 3 \mathrm{DM} \% 26$ everyone $\% 3 \mathrm{D} \% 26$ city $\% 3 \mathrm{DLisboa} \% 26$ library $\% 3 \mathrm{D} \% 26$ shelfmark $\% 3 \mathrm{D} 2294 \%$ 26daterange $\% 3 \mathrm{D} \% 26$ placeofprod $\% 3 \mathrm{D} \% 26$ scribe $\% 3 \mathrm{D} \% 26$ publisher $\% 3 \mathrm{D} \% 26$ prevowner $\% 3$ $\mathrm{D} \% 26$ assocname $\% 3 \mathrm{D} \% 26$ subject $\% 3 \mathrm{D} \% 26$ text-join\%3Dand $\% 26$ browseout $\% 3 \mathrm{Dmsed} \% 26$ so rt\%3Dtitle>. Además de otros detalles a los que se aludirá también en este trabajo, en ambos recursos electrónicos se señala, en efecto, H-5-39 como antigua signatura del manuscrito.

${ }^{13}$ Para la cronología de los principales cuños utilizados por la BNP, cfr. el catálogo de la exposición Do Terreiro do Paço ao Campo Grande. 200 anos da Biblioteca Nacional, Lisboa, Biblioteca Nacional, 1997, p. 164.
} 
Quizá en la identificación de anteriores propietarios del códice no sea irrelevante examinar las cartas manuscritas de los interlocutores de Cenáculo ${ }^{14}$ para determinar si algunas de las notas marginales que salpican el códice (cfr. infra) pueden corresponder a alguno de aquellos. En este sentido es sumamente elocuente la información que ofrece el último folio del mismo, el fol. 60 (el 59 en la numeración primitiva, cfr. infra): en él pueden leerse tres notas marginales, de las que la que se descifra con mayor (aunque no total) claridad es una de las dos que figura en el margen inferior del verso del folio (encontrándose la otra en el margen derecho del recto) y que, según se reproduce en la citada ficha en línea de la BNP, lo que dice «em letra esmaecida» es exactamente «este liuro est Antonius Domingez (f. 59 v)». Al igual que las otras de más difícil interpretación, esta sería una marca de posesión del manuscrito y en ese «Antonius Domingez» quizá podría verse una referencia a António Domingues do Passo. Este personaje estuvo implicado con Cenáculo en la educación del príncipe da Beira, D. José, nieto del rey D. José I e hijo de D. Maria I: en la Cópia da Instrução, e Ordens que Sua Magestade foi servido para dar para se observarem no quarto do Príncipe Nosso Senhor, Cenáculo aparece como «confessor» y António Domingues do Passo como «instrutor de ler, e escrever» del príncipe ${ }^{15}$. La relación entre ambos personajes viene evidenciada, asimismo, por las varias cartas que intercambiaron, cuando, después de la muerte de D. José I en

${ }^{14}$ Para la nutrida correspondencia epistolar entre Cenáculo y diversas personalidades (libreros e intelectuales entre ellas), con información sobre compra e intercambio de libros (entre otros aspectos), cfr. Armando Nobre de Gusmão, Catálogo da Correspondência dirigida a Fr. Manuel do Cenáculo Vilas Boas, Évora, Biblioteca Pública e Arquivo Distrital, 1944-1956, 6 vols.; Francisco António Lourenço Vaz, Márcia Ferreira Oliveira y Patrícia Monteiro, Os livros e as bibliotecas no espólio de D. Frei Manuel do Cenáculo: repertório de correspondência, róis de livros e doações a bibliotecas, Lisboa, Biblioteca Nacional de Portugal, 2009; Francisco António Lourenço Vaz (coord.), Correspondéncia inédita dirigida a D. Frei Manuel do Cenáculo. As cartas de Joaquim Sa \& Alexandre Faria Manuel, Universidade de Évora, Cidehus, 2015.

${ }^{15}$ Este texto se encuentra en los fols. $231 \mathrm{r}-237 \mathrm{v}$ del Diário de Frei Manuel do Cenáculo (Biblioteca Pública de Évora, Códice CXXIX/1-17, digitalizado en <http://www.bdalentejo. net/BDAObra/BDADigital/Obra.aspx?id=313\#>) y es una copia de las Instruções de D. José I del 7 de diciembre de 1768: el documento estaba centrado en las pautas para la educación de su nieto, pues, según los dictados del ministro Pombal, tenía que ser sucesor al trono, aunque, por su temprana muerte en 1788, acabaría ocupándolo su hermano D. João VI. Para la reproducción del texto, cfr. Manuel Filipe Cruz M. Canaveira, Sua Majestade Fidelíssima: da monarquia, imagem da realeza ideal e educação do rei no absolutismo português e europeu, Lisboa, Universidade Nova de Lisboa-Faculdade de Ciências Sociais e Humanas, dissertação de doutoramento, 1996, pp. 595-599. Sobre la importancia de las Instruções para estudiar la formación del nieto de D. José I, vid. Maria Beatriz Nizza da Silva, «A educação de um príncipe no período pombalino», Revista de História das Ideias, 4/1 (1982), pp. 377-383. Las Instruções fueron redactadas cuando el príncipe D. José tenía 7 años y, si con esa edad Cenáculo era el confesor y encargado de la formación religiosa, parece que, entre los 9 y los 15 años de la vida de aquel, también fue su maestro y le ofreció enseñanzas sobre legislación, historia o geometría. Vid. Francisco da Gama Caeiro, Frei Manuel do Cenáculo. Aspectos da sua actuação filosófica, Lisboa, Instituto de Alta Cultura-Centro de Estudos de Psicologia e de História da Filosofia, 1959, pp. 85-89. 
1777 y la consiguiente pérdida de poder del marqués de Pombal en la corte, Cenáculo se marchó a Beja para ocupar el cargo de obispo de aquella diócesis que le había sido concedido en 1770, de manera que António Domigues do Passo se convirtió en interlocutor de Cenáculo en la corte y en Lisboa entre 1777 y 1787, esto es, en tiempos de D. Maria I. La consulta de las misivas dirigidas por António Domingues a Cenáculo desde Lisboa y Vila Viçosa, y custodiadas en la Biblioteca Pública de Évora, podría ayudar a determinar si la letra de las mismas coincide con la de aquella nota de posesión del fol. $60 \mathrm{v}$ del códice lisboeta y si, por lo tanto, António Domingues habría sido su propietario y quien se lo pudo ofrecer al obispo de Beja. De haber sido así, muy probablemente el instrutor del príncipe da Beira habría dado el manuscrito a Cenáculo antes de la marcha de este para Beja, pues ninguna de las cartas enviadas por Cenáculo a António Domingues hace referencia a un particular que el bibliófilo no habría dejado de agradecer ${ }^{16}$.

Lo que sí se encuentra en el Catálogo y la Copia son los que podrían considerarse como primeros intentos o esbozos de descripción del ejemplar. De la escueta información que arrojan parece desprenderse, como se ha apuntado, que se trata de un manuscrito formado por un volumen in folio en el que fue reproducido un $L A$ (análogos detalles en la ficha en papel anteriormente referida en la que se da la primitiva signatura, cfr. n. 11) y que, según podrían sugerir las indicaciones «do tempo d'El Rey D. Dinis» y con «letra de então», se habría confeccionado en el siglo XIV, lo que podría llevar a identificar, incluso, el testimonio con el original de la obra, pues, como ya fue dicho, el $L A$ se redactó en 1318 por encargo del monarca portugués. No obstante, los lacónicos apuntes son imprecisos, o más bien inciertos, tanto en lo relativo al contenido del códice como a su cronología.

En la segunda mitad del siglo XIX, Francisco Martins de Andrade (1810-1878) subsanó algunas de aquellas apreciaciones, aunque manteniendo ciertos datos erróneos. Nombrado conservador-ajudante de la «Repartição de manuscritos e antiguidades» de la Biblioteca el 7 de diciembre de 1836 y conservador de dicha «Repartição» el 6 de junio de 1862, Andrade elaboró un inventario de los documentos que habían entrado en la institución agrupándolos por su contenido: en los fols. 30v-32r de ese repertorio de Manuscritos Paleographicos da Biblioteca Nacional de Lisboa, de acceso restringido en dicho centro (CÓD. 11141), se informa de un ejemplar sobre cuya identificación con el CÓD. 2294 no ofrece dudas el hecho de que se identifique con la signatura alfanumérica $\mathrm{H}-5-39$ con la que inicialmente se catalogó (cfr. supra). Describe Andrade el testimonio como «1 Vol.»,

${ }^{16}$ Un resumen del contenido de las siete cartas de Cenáculo a António puede leerse en Vaz, Oliveira y Monteiro, Os livros e as bibliotecas, op. cit., pp. 255-257. Tampoco las cartas que Do Passo envía al obispo aluden a tal episodio, según nos ha informado gentilmente el profesor Francisco António Lourenço Vaz. 
con formato «fol.», «em Papel», por aquel entonces aun «Inedito» y en el que se incluye el «Livro de Alveitaria» de Mestre Giraldo. Añade el estudioso que el volumen «he escripto em 59 meias folhas de letra corrente, e toda igual» y que se trata de una «copia, que quando muito, segundo nosso entender, pode tocar no fim do Seculo XIV». El conservador-ajudante proporciona, como se ve, detalles que completan o matizan la descripción del manuscrito (algunos aun inexactos como el de la cronología y el número de folios) y, por otro lado, introduce datos relativos a su contenido que no se habían recogido en los catálogos previos: según el estudioso, además de una copia del $L A$, cuyo prólogo reproduce ${ }^{17}$, el ejemplar «tem por accressimo hũa especie de terceira Parte, em que trata das Aves Caçadoras, suas molestias».

\section{CONTENIDO}

En efecto, no es el manual de veterinaria escrito por el Mestre Giraldo el único texto transmitido por el códice donado por Cenáculo. Al Livro de Alveitaria (BITAGAP, texid 1099), cuya copia se extiende hasta el fol. $45 \mathrm{r}^{18}$, le sigue otra obra sin título y encabezada con la «Tauoa dos capitollos das aues caçadores» (fol. 45v), que se extiende hasta el final del manuscrito (fol. 60v) (BITAGAP, texid 1098). La existencia de este segundo texto es una realidad conocida al menos desde el siglo XVII, pues algunos bibliógrafos peninsulares, partiendo probablemente del manuscrito que tratamos (sin que se pueda determinar si accedieron a él o tuvieron noticias indirectas del mismo), aluden a ese segundo texto, que atribuyen también al Mestre Giraldo ${ }^{19}$. Como bien refiere Carolina Michaëlis de Vasconcellos, «É

${ }^{17}$ Andrade constata un cierto desajuste entre el prólogo y el mismo texto en lo relativo al número de capítulos: si bien el prólogo cuenta en 77 los capítulos del $L A$, «só achamos na Obra-dice Andrade- 61 Capitulos, sem que pareça faltar-lhe coiza alguma». La apreciación es fruto de un descuido, pues 61 son los capítulos que tiene la segunda de las dos partes en que se estructura el Livro, de manera que el conservador-ajudante no toma en consideración los que formarían la primera parte. Adviértase, no obstante, que el cómputo de capítulos que hace el prólogo parece erróneo, pues la obra distribuye la materia en dos partes, formadas respectivamente por 17 y 61 capítulos, lo que hace un total de 78 y no 77 .

${ }^{18}$ Aunque el explicit reproducido supra figura entre el final del fol. $43 \mathrm{v}$ y el inicio del fol. 44r, después de él, hasta el fol. 45r, se incorporan cinco capítulos que muy probablemente no debían de formar parte de la obra original y que, por lo tanto, habrían sido «redigidos por outro autor que não Mestre Giraldo», en palabras de António Franco, «O Livro de Alveitaria do mestre Giraldo numa perspectiva da Linguística do Texto de Especialidade», en Luis Adão da Fonseca, Luis Carlos Amaral y Maria Fernanda Ferreira Santos (coords.), Os Reinos Ibéricos na Idade Média. Livro de homenagem ao Professor Doutor Humberto Carlos Baquero Moreno, Porto, Civilização, 2003, vol. I, pp. 209-217, p. 210.

${ }^{19}$ Un rápido repaso por la cuestión puede verse en Luis Krus, «Livro de Falcoaria», en Lanciani y Tavani (coords.), Dicionário, op. cit., pp. 408-409; Gerardo Pérez Barcala, «El cód. 2294 de la Biblioteca Nacional de Portugal y el falso libro de cetrería del Mestre Giraldo: revisitando un problema de atribución», en Esther Corral Díaz, Elvira Fidalgo Francisco y Pilar Lorenzo Gradín (eds.), Cantares de amigos. Estudos en homenaxe a Mercedes Brea, Santiago de Compostela, Universidade de Santiago de Compostela, 2016, pp. 711-722. 
pois únicamente em virtude de se haver o Livro das Aves propagado num mesmo manuscrito com o dos Cavalos que os bibliógrafos peninsulares consideraram como autor o físico de D. Denis $»^{20}$.

Que la letra del códice sea «toda igual», recordando las palabras de Andrade, y que la obra iniciada con la Tauoa carezca de datos sobre su autoría han forjado, en efecto, una falsa hipótesis que en el siglo XVII pasó de Jorge Cardoso (1606-1669) a Nicolás Antonio (1617-1684). Basándose en la información que, a partir de la consulta directa de un manuscrito in folio, Jorge Cardoso había recogido para la redacción de una ambiciosa Bibliotheca Lusitana, el bibliógrafo hispalense se refiere al Mestre Giraldo como autor de las dos obras en su Biblioteca Hispana Vetus, que vio la luz póstumamente en 1696:

Eiusdem Regis [scil. D. Denis] praecepto obsequutus GIRALDUS quidam, scripsit librum De albeiteria y volateria, hoc est, veterinariae artis \& accipitrariae, quam vidit MS. in folio idem Georgius Cardosus, inque schedis laudatis annotatum reliquit ${ }^{21}$.

Apoyándose en estas informaciones, Diogo Barbosa Machado (1682-1772) alude también a Mestre Giraldes (sic) como responsable de un Livro de Alveitaria y un Arte de Volateria en su Bibliotheca Lusitana, publicada entre 1741 y 1758 . La sinopsis que hace del $L A$, «dividido em duas partes», formado por «77. Capitulos» y «escrito em Lisboa no anno de $1318 »^{22}$, coincide con cuanto se dice de esa obra en el CÓD. 2294 (cfr. supra), por lo que es probable que el bibliógrafo lisboeta hubiese tenido directa o indirectamente noticias de ese manuscrito, quizá a través del mismo Cenáculo con quien aquel mantenía probados contactos ${ }^{23}$.

\footnotetext{
${ }^{20}$ Carolina Michaëlis de Vasconcellos, «Mestre Giraldo e os seus tratados de alveitaria e cetraria», Revista Lusitana, 13/3-4 (1910), pp. 149-432, p. 172.

${ }^{21}$ Nicolao Antonio Hispalensi, Biblioteca Hispana Vetus, sive Hispani scriptores qui ab Octaviani Augusti aevo ad annum Christi MD. floruerunt, Tomus secundus, Matriti, apud viduam et heredes D. Joachimi Ibarrae, 1788, p. 144 (liber IX, caput IV, §202).

${ }^{22}$ Diogo Barbosa Machado, Bibliotheca Lusitana Historica, Critica, e Cronologica, Tomo II, Lisboa, Officina de Ignacio Rodrigues, 1747, p. 385, s. v. Mestre Giraldes.

${ }^{23}$ Testimonio de la amigable relación de Barbosa Machado con el obispo de Beja son las cartas datadas en 1770 que el primero dirige al segundo. En una de las misivas a Cenáculo, así como en otra a Nicola Pagliarini, el abad de Sever deja constancia de las negociaciones con ambos personajes para que sus libros fuesen ofrecidos al rey D. José e incorporados a la Biblioteca Real, que, alimentada con tanto esmero por D. João V con importantes adquisiciones, se había visto considerablemente dañada por el terremoto ocurrido en Lisboa el 1 de noviembre de 1755. Para las relaciones epistolares de Barbosa Machado con Cenáculo y otros intelectuales y bibliófilos de la época, así como para la integración de su vasta colección en la Biblioteca Real y la mediación de Cenáculo en el proceso, vid. Mário Alberto Nunes Costa, «Em torno da correspondência de Diogo Barbosa Machado», Boletim da Biblioteca da Universidade de Coimbra, 41 (1992), pp. 1-104 (las dos misivas a Cenáculo se reproducen en las pp. 100-101 y 102-103); Lilia Moritz Schwarcz, «Sobre a longa viagem da biblioteca dos reis», en Eliana de Freitas Dutra y Jean-Yves Mollier (orgs.), Política, nação e edição. O lugar dos impressos
} 
Andrade se hace eco en una nota de cuanto habían afirmado estos estudiosos y sugiere que la parte del manuscrito sobre las aves caçadores «he talvez a Volateria, que cita Barboza». A principios del siglo xx, Gabriel Pereira (1847-1911) se manifestó en la misma dirección. Como personaje estrechamente vinculado a la BNP y buen conocedor de sus fondos ${ }^{24}$, editó las dos obras incluidas en el CÓD. 2294, asignándoselas, en efecto, al Mestre Giraldo y ofreciendo datos sobre el volumen que modifican -y corrigen- algunas de las informaciones previas sobre el mismo. En sus transcripciones de los dos textos reproducidos en el ejemplar lisboeta el estudioso se pronuncia en los siguientes términos:

El rei D. Diniz encarregou o seu phisico, ou medico, mestre Giraldo, de lhe escrever um livro de alveitaria, em português. Giraldo consultou os livros que tratavam do assumpto, traduziu, compilou, formou a obra que terminou em 1318. E escreveu ainda outro tratado especial sobre as enfermidades das aves de caça. Os escriptos originaes pederam-se, mas existe uma copia feita no seculo xv.

Forma essa copia o cod. $n^{\circ} 2.294$ do fundo antigo da Bibliotheca Nacional de Lisboa. O tratado de alveitaria está completo. $\mathrm{O}$ das aves tem 17 capitulos, completos, a seguir, e parte do $18^{\circ}$ faltando os últimos 5 capitulos. $O$ códice tem paginação seguida, a linguagem e a forma da letra mantem-se igual. Por isto podemos attribuir o tratado das aves a mestre Giraldo, porque no tratado das molestias dos cavallos está declarado o nome do auctor, e Barbosa Machado nos afirma que o phisico delrei D. Diniz escrevera os dois livros ${ }^{25}$.

Barbosa Machado, [...], dá noticia de mestre Giraldo, physico ou medico de elrei D. Dinis, e autor de um tratado de alveitaria, e de outro das enfermedades das aves de caça. Pela concisão da noticia, parece que o illustre bibliographo não teve presente a obra. A

na construção da vida política. Brasil, Europa e Américas nos séculos XVIII-XX, São Paulo, Annablume, 2006, pp. 11-45.

${ }^{24}$ Pereira fue llamado en 1887 por el entonces director de la BNP, António Enes, para auxiliarlo en los trabajos de reorganización del centro que emprendió en su fugaz dirección de la institución (1886-1887). Su empresa fue de crucial importancia en la «colosal empresa de reorganização maciça, completa, integral dos depósitos da Biblioteca Nacional de Lisboa. [...] A notação topográfica que até aí era complicada e obscura, feita per letras, em função das salas, estantes, prateleiras e localização das espécies em cada prateleira, passou a fazer-se por números, por isso muito mais clara, simples e fácil [cfr. lo expuesto supra sobre los cambios en el sistema de catalogación de los fondos de la BNP]. É evidente que tão radical modificação obrigou à revisão dos verbetes catalogares de todas as espécies, a fim de serem substituidas as cotas. Assim, passaram-lhe pelas mãos -um a um-as centenas de milhar de libros e opúsculos da Biblioteca para a recatalogação. Devido a ese herculeo trabalho, à sua prodigiosa memória e ao seu labor constante, Gabriel Pereira tornou-se um autêntico catálogo vivo e uma verdadeira bibliografia animada da sua Biblioteca». Son palabras de António Ferrão, «Gabriel Pereira: a sua educação e cultura; a sua época e a sua obra», Anais das Bibliotecas e Arquivos de Portugal, S. 2, 19/73-74 (1947), pp. 61-84, concretamente, p. 66.

${ }^{25}$ Gabriel Pereira, Mestre Giraldo. Tratado das enfermidades das aves de caça (Segundo um manuscripto do seculo XV), Lisboa, Officina Typographica, 1909, p. 3. 
Bibliotheca Nacional de Lisboa possue uma copia feita no seculo XV. Está contida no codice $\mathrm{n}^{\circ} 2.294$ da collecção geral dos manuscritos, o qual contém tambem do mesmo autor um Tratado das enfermedades das aves de caça, incompleto, $[\ldots]^{26}$.

Como se ve, la autoridad de Barbosa Machado llevó a Pereira a atribuir al Mestre Giraldo el segundo de los textos reproducidos en el volumen. Pero el investigador también apoya paradójicamente su argumentación en la uniformidad de la letra de un códice que, según él mismo indica, no transmite los textos originales. El persistente error -que parece sustentarse en la desafortunada confusión de autor y copista para textos que no son autógrafos- en la identificación y atribución de la obra incluida entre los fols. $45 \mathrm{v}-60 \mathrm{v}$ del códice fue corregido por Manuel Rodrigues Lapa: el estudioso vio en dicho texto una copia, incompleta, de la misma obra que se reproduce en los fols. 30r-68v del CÓD. 518 de la sección Pombalina de la BNP y que no es otra que el célebre Livro de falcoaria escrito entre 1345 y 1383 por encargo del rey don Fernando I de Portugal por su halconero Pero Menino ${ }^{27}$. Se resuelve de este modo el asunto relacionado con el contenido del CÓD. 2294, que no solo incluye, pues, el $L A$, según constaba en los catálogos relativos a la donación de Cenáculo ${ }^{28}$. Y se hace evidente al tiempo que, siendo una sola la mano que interviene en la reproducción de dos obras de autores diferentes (Mestre Giraldo y Pero Menino), esas no pueden ser originales sino copias de las mismas, como ya había reconocido Pereira y antes de él Andrade, aunque manejando argumentos, como se ha dicho, poco afortunados.

\footnotetext{
${ }^{26}$ Pereira, «Livro d'Alveitaria», ed. cit., p. 1.

${ }^{27}$ Manuel Rodrigues Lapa, Livro de Falcoaria de Pero Menino, Coimbra, Imprensa da Universidade, 1931. Señala el estudioso portugués que el CÓD. 2294 de la BNP-que identifica como $B$ en la transmisión del texto de Menino- es «substancialmente idêntico a $A$ [ $=\mathrm{BNP}$, sección Pomb, CÓD. 518], pero representa «pelo que respeita à linguagem, uma redacção diferente e tem, comparado àquele, a notável inferioridade de estar incompleto no princípio e no fim. No princípio, falta-lhe a ordem de D. Fernando que determinou Pero Menino a escrever o tratado, o índice inicial das mezinhas, e no fim os capítulos 19-24, que são considerados contudo no índice [cfr. infra]» (p. xxix). Para Lapa, $A$ representa la versión más próxima al original de Menino, siendo «duma cópia semelhante a esta que Pero López de Ayala, [...], se serviu para a composição do Libro de la caza de las aves [...], acabado em junho de 1386» (ibid.). Con respecto a $A$, «o copista de $B$ teria alterado uma ou outra expressão duma língua, que tinha sofrido já uma evolução de mais de meio século, e já não era bem a sua» (p. xxxi).

${ }^{28}$ No obstante, a pesar de que Lapa subsana el error en la atribución del segundo texto, algunos estudiosos posteriores, partiendo muy probablemente de las valoraciones de Gabriel Pereira, siguen reiterando que el segundo texto sería también de la autoría del Mestre Giraldo. Apuntan, por ejemplo, Oliveira Camargo, Iannone y Cury (Textos medievais portugueses, op. cit., p. 7) que Mestre Giraldo es «autor de um livro de alveitaria e de outro que trata das Enfermidades das Aves de Caça, incompleto». En la misma dirección, Sheila R. Ackerlind (King Dinis of Portugal and the Alfonsine Heritage, New York, Peter Lang, 1990, p. 25) refiere que, por encargo de don Denis, Mestre Giraldes (sic) compiló «two treatises on veterinary medicine: the Livro d'Alveitaria, concerning the care of horses, and the Tratado das Enfermidades das Aves de Caça, about falconery. Mestre Giraldes wrote these studies after summarizing and translating various foreign on veterinary medicine».
} 


\section{CRONOLOGÍA Y DESCRIPCIÓN}

Además de información inexacta en relación con el contenido del volumen, los primeros documentos que se refieren a él también se mostraban confusos al respecto de su cronología: si la Copia apuntaba que el códice era de la época de don Denis y Andrade lo databa a finales del siglo XIV, Pereira lo sitúa a finales de la siguiente centuria:

O codice do mestre Giraldo é um in-folio pequeno, de 270 millimetros de altura por 195 de largura. Esta escripto em 59 paginas numeradas na frente. $O$ papel bastante empardecido, a tinta preta um tanto esvaida; iniciaes, sem arte, toscas, avivadas por tinta vermelha. A filigrana do papel é mão e estrella, marca ainda usada no fim do seculo Xv. Em media a pagina tem 30 linhas escriptas, em caracteres nítidos, cursivo do seculo $\mathrm{XV}$, com suas abreviaturas ${ }^{29}$.

La materialidad del testimonio apunta hacia esta cronología, pues en varios de sus folios $(2,4,7,8,10,12,13,18,20,21$, etc.) aparece una filigrana análoga a la marca que Arnaldo Faria de Ataíde e Melo describe como «mão dereita enluvada, com um B na palma, sob estrêla de 6 pontas», que data en $1496^{30}$. Así pues, el tratado de veterinaria redactado por el físico de don Denis a principios del siglo XIV y una copia del Livro de falcoaria escrito en la segunda mitad de esa misma centuria por el halconero de don Fernando I se conocen (en el primer caso, de forma exclusiva) a través de un pequeño volumen en papel de finales del siglo $\mathrm{XV}^{31}$. Aunque no se ha podido precisar

\footnotetext{
${ }^{29}$ Pereira, Mestre Giraldo. Tratado das enfermedades, ed. cit., p. 5. En análogos términos se expresa el estudioso en la edición del $L A$ : «É um in-folio, de 270x195 millimetros com 59 folhas. A pagina tem na media 30 linhas, escritas em caracteres nítidos, cursivo da epoca, com bastantes abreviaturas» (Pereira, «Livro d'Alveitaria», ed. cit., p. 1). De Pereira parece tomar Vasconcellos, («Mestre Giraldo e os seus tratados», art. cit.), los detalles sobre el códice, que describe como «cartáceo» (p. 151), «De papel ceutí?» (p. 151, n. 2), formado por 59 folios, en el que «Cada página in-fol., tem 30 linhas, termo médio» (p. 151, n. 1), y con unas dimensiones de los folios «de 270x195 millimetros» (p. 175).

${ }^{30}$ Arnaldo Faria de Ataíde e Melo, O papel como elemento de identificação, Lisboa, Oficinas Gráficas da Biblioteca Nacional, 1926, lám. 1, fig. nº 4, y p. 35. Basándose en la autoridad de Ataíde e Melo, en la ficha del catálogo en línea de la BNP y en BITAGAP manid 1044 se informa de que el códice data de «ca 1496». Probablemente alguna de estas sea la fuente en la que se basa José Manuel Fradejas Rueda («Aproximación a la literatura cetrera portuguesa», eHumanista, 8, 2007, pp. 197-226, p. 201, n. 15) para afirmar que el manuscrito fue «copiado hacia 1496».

${ }^{31}$ Después de Pereira, es común la aceptación del siglo xv para la datación del ejemplar, aunque con vacilaciones en el arco temporal. Así, por ejemplo, Vasconcellos («Mestre Giraldo e os seus tratados», art. cit., p. 151) se refiere a este códice como «apógrafo, do século XV»; Rodrigues Lapa (Livro de Falcoaria, ed. cit., p. xxix) lo describe como de «meados do século xv», y Serafim da Silva Neto (Textos medievais portuguêses e seus problemas, Rio de Janeiro, Ministerio de Educação e Cultura-Casa de Rui Barbosa, 1956, p. 93) dice que es una «colectânea apógrafa do séc. XV». Sobre la generalización del uso y de la fabricación del papel en Portugal en este siglo, vid., por ejemplo, António Henrique de Oliveira Marques, Portugal na Crise dos Séculos XIV e XV, Lisboa, Editorial Presença, 1987 (= Joel Serrão y António Henrique de Oliveira Marques (dirs.), Nova História de Portugal, vol. IV), pp. 52-53; Maria José Ferreira dos
} 
el scriptorium en el que en esa época se habría confeccionado el códice, la propia naturaleza de los textos que en él se reproducen hace probable vincular su elaboración con un ámbito aristocrático, pues se trata de dos obras que eran de particular interés en ese espacio. El $L A$ está dedicado a los cuidados del caballo, convertido en la Edad Media en signo de distinción social de las clases elevadas, que debían poseer conocimientos para preservarlos según había establecido, por ejemplo, Alfonso X en la ley 10 del título XXI de la Partida Segunda: refiere, en efecto, el Rey Sabio que «los cavalleros deven seer sabidores de conoscer las bestias», «saberlos [scil. a los caballos] mantener en sus bondades», «sy alguna mala costunbre oviesen tollerlos della» y «guarescerlos de las enfermedades que oviesen ${ }^{32}$. Por su parte, el Livro de falcoaria se centra en las atenciones que merecían los animales con los que se practicaba uno de los pasatiempos más importantes de la aristocracia y cuya posesión denotaba la superioridad social de quienes los poseían ${ }^{33}$.

Por lo que a la descripción externa del códice se refiere, Andrade y Pereira señalaron, respectivamente, que está formado por «59 meias folhas» $\mathrm{y}$ «59 paginas numeradas na frente», reproduciéndose el dato en la ficha dedicada al ejemplar en BITAGAP, manid 1044 («ff.: 59»). Tal apreciación ha de manejarse, no obstante, con cautela, pues, dejando a un lado la cubierta «em pergaminho liso com vestígios de atilhos» (así la describe la ficha del catálogo en línea de la BNP) $)^{34}$ y las hojas de guarda -de introducción tardía ${ }^{35}$-, el códice está formado por 60 folios. El desajuste entre las caracterizaciones

Santos, «Marcas de água e historia do papel: a convergência de um estudo», Cultura. Revista de História e Teoria das Ideias 33 (2014), pp. 11-29. [En línea], [consulta: 23/5/2017].

${ }^{32}$ Aurora Juárez Blanquer y Antonio Rubio Flores, Partida Segunda de Alfonso X el Sabio. Manuscrito 12794 de la B.N., Granada, Impredisur, 1991, pp. 182-183.

${ }^{33}$ Cfr. Pero Lopez de Ayala, Livro de la caça de las aves. El Ms. 16.392 (British Library, Londres), John G. Cummins (ed.), London, Tamesis, 1986, pp. 18-23. Ayala destaca la importancia de la presencia de los halconeros en las cortes reales: además de mencionar a Menino, cuya obra maneja como fuente principal, se refiere a otros de la corte de Pedro I de Castilla como Iohan Ferrandes Burielo, Alfonso Mendez, Ruy Gonçalez de Yllescas y Iohan Criado (ibid., pp. 16-17).

${ }^{34}$ En la portada, de $272 \times 190 \mathrm{~mm}$., figura una cifra, 1656, que podría corresponder a una signatura antigua, si es que no se trata de una portada de otro libro que el elevado precio del pergamino «obligó» a reaprovechar.

${ }^{35}$ Las guardas que protegen el contenido del manuscrito se habrían introducido en el siglo XIX, o al menos utilizando papel de esa época. Así lo revelan las marcas de agua, diferentes, de la guarda inicial (Gilling \& Allford 1823) y final (con el escudo y nombre del fabricante GiorMagnani). En relación con esta última, se sabe que en el siglo xIX los hermanos italianos Magnani, Giorgio y Domenico, poseían varias fábricas en la ciudad toscana de Pescia, convertidas en centros de producción de un tipo de papel que se distribuyó por todo el mundo: en Portugal, concretamente, el imperio papelero italiano tenía una filial. Sobre el papel de GiorMagnani y sus diferentes tipos de filigranas a partir de algunos documentos procedentes de países hispanoamericanos, donde fue muy común este tipo de papel, vid. José Carlos Balmaceda, «Los Magnani: papeles y filigranas en documentos Hispanoamericanos», en Actas del VIII Congreso Nacional de Historia del Papel en España, [Madrid], Asociación Hispánica de Historiadores del Papel, 2009, pp. 51-70. Vid. también Ferreira dos Santos, «Marcas de água», art. cit., p. 3; Rosicleide Rodrigues Garcia, «Estudo paleográfico e codicológico dos 
de aquellos estudiosos y la propia materialidad del ejemplar tiene su origen en un error en la paginación provocado por la asignación del número 28 a dos folios consecutivos, como se expone en la ficha en línea de la BNP. En efecto, el CÓD. 2294 está compuesto por 60 folios que fueron numerados en el margen superior derecho de forma progresiva con cifras árabes del 1 al $59^{36}$, pero a dos folios consecutivos les fue adjudicado el número 28. El descuido fue subsanado a partir del punto exacto en que tuvo lugar, de tal manera que, bajo la cifra 28 que se adjudica al segundo folio así numerado, la errada foliación se corrige con una indicación a lápiz «alias 29» que se repite en los folios siguientes -bajo los numerados como 29 y 30 se escribe «alias 30»y «alias 31» respectivamente-, apuntando simplemente a partir del folio inicialmente numerado como 31 la cifra 32 que corresponde a la nueva numeración y así sucesivamente hasta llegar al último folio del códice en el que, bajo la cifra 59, se escribe a lápiz la correcta 60. Para la reparación de aquella errada foliación podría darse una cronología que sería posterior a 1910 y anterior a la década de los años 80 de esa centuria. Es, en efecto, muy probable que, si Pereira (y, antes de él, Andrade) no refiere la cuantía real de páginas del códice, es porque la corrección que subsana el error de foliación no estaba en el manuscrito en la primera década del siglo $\mathrm{xx}$, que es la época de la que datan sus transcripciones de las dos obras copiadas en el manuscrito. La corrección de la foliación se encuentra, en cambio, en las dos copias microfilmadas del ejemplar, F 465 y F 257 (y no 267 como se indica en BITAGAP), la segunda de las cuales debió de realizarse en 1983, si la cifra 3/2/83 que se lee en la primera imagen del mismo corresponde a la fecha en la que se procedió al microfilmado del códice. Así pues, para la moderna foliación a lápiz del ejemplar-que cuenta en 60 y no en 59 el número de sus foliospuede ofrecerse una cronología que se sitúa post 1910 y ante 1980.

En lo que toca a la distribución de esos 60 folios, a ella probablemente iría dirigida, según ya se ha señalado, la indicación «fol.» del Catálogo, de la Copia y de Andrade, así como la observación de

documentos de Capivari do século XIX», disponible en $<$ http://dlcv.fflch.usp.br/sites/dlcv.fflch. usp.br/files/05_9.pdf> [consulta: 18/4/2017].

${ }^{36} \mathrm{El}$ responsable de la paginación inicial del manuscrito podría identificarse con la mano que en los márgenes de varios folios escribe la numeración arábiga correspondiente a la romana de algunos capítulos de la segunda parte del $L A$ : cfr. «46» para «O Rbj capitollo he dos emsartilhamentos que aueem aos cauallos» (fol. 36v, lín. 10-11), «47» para «O Rbij capitollo he das estrepaduras que aqueeçe $m$ aos cauallos nos geolhos ou nas outras Junturas $e$ nos outros logares das pernas» (fol. 37r, lín. 14-17), «48» para «O Rbiijo capitollo he de huũa Jnfirmjdade que he dicta em latym furjna $\mathrm{E}$ em nossa linguagem inchaço duro que se faz na coroa da unha hu se Junta a carne com ella» (fol. 37v, lin, 13-16), «49» para «O Rix capitollo he do cançer» (fol. 37v, lín. 25), «50» para «O L ${ }^{\text {ta }}$ capitollo he das fistollas» (fol. 38v, lín. 8), «55» para «O $\mathrm{Rb}$ capitollo he das sedas e das gretas que sse fazem nas hunhas dos cauallos» (fol. 40r, lín. 1112), «56» para «O Rbj capitolo he das encrauaduras» (fol. 40v, lín. 12), «57» (con 5 corregido sobre 4) para «O Rbij capitollo he das encrauaduras que fumegam $e$ das empedraduras» (fol. 41v, lín. 1). 
Pereira de que «é um in-folio». Como se sabe, este término técnico designa a la hoja de papel que, doblada al medio una sola vez, da lugar a dos folios (es decir, cuatro páginas) ${ }^{37}$. De tal plegado in folio resulta cada uno de los bifolios que constituyen el manuscrito. Como parecen indicar las costuras, este se habría organizado en su origen en cinco fascículos regulares (y completos), cada uno de los cuales está formado por 6 bifolios, lo que hace un total de 12 folios por cuaderno, de modo que el códice parece organizarse en cinco seniones regulares. Con todo, la distribución de algunos cuadernos no está exenta de dificultades, que muy probablemente tienen que ver con la reencuadernación a la que el ejemplar fue sometido en el momento en el que se introdujeron las guardas (cfr. n. 35). Estas, en efecto, parecen pegadas a los dos folios más externos de los cuadernos respectivos, el primero y el quinto, de manera que debió de alterarse la materialidad de los bifolios en los que aquellos folios se integraban.

Al respecto de las proporciones reales del ejemplar podría plantearse que este se halle mutilado en su sección final. A favor de tal hipótesis podría aducirse el hecho de que el manuscrito concluya en el fol. 60v sin dar por terminada, como ya se ha dicho (cfr. n. 27), la exposición del «Capitollo xviij ${ }^{\circ}$ da frjelldade que per mujtas vezes entra a frjeldade no papo $e$ no bucho $e$ nas trjpas da aue» (fol. $60 \mathrm{v}$, lín. 8-10) del Livro de falcoaria y sin incluir los seis capítulos que, según la Tauoa que presenta dicha obra en el manuscrito, seguirían a aquel $^{38}$. Esta circunstancia apoyaría la conjetura de que en su origen el manuscrito era de mayores dimensiones, según una hipótesis que Gunnar Tilander concretó en las afinidades textuales que existen entre la versión del Livro de falcoaria transmitida por el CÓD. 2294 y el Livro de citraria de Francisco de Mendanha, del siglo XVI, conservado en el ms. Sloane 821 de la British Library, fols. 46-72 (códice que también incluye, fols. 5v-20, otra versión de Pero Menino), y

${ }^{37}$ Vid., por ejemplo, Elisa Ruiz García, Introducción a la codicología, Madrid, Fundación Germán Sánchez Ruipérez, 2002, pp. 150, 151-152; Maria Isabel Faria y Maria da Graça Pericão, Dicionário do Livro. Da escrita ao livro electrónico, Coimbra, Edições Almedina, 2008, p. 666, s. v. in folio.

${ }^{38}$ Se trata de los siguientes capítulos: «Capitollo da ferjda aberta $e$ çarada», «Capitollo da queeda o derramadura», "Capitollo do olho quebrado», "Capitollo das trjpas que ssom fora», «Capitollo das queixadas que ssom ffora» $\mathrm{y}$ «Capitollo pera a aue auer de mudar bem» (fol. 45v, lín. 19-24). Inexactas son, por tanto, la apreciaciones de Pereira (y, antes de él, Andrade), según el cual al tratado de las aves caçadores le faltan los últimos cinco capítulos; de Vasconcellos («Mestre Giraldo e os seus tratados», art. cit., p. 151), para quien «No fim faltam uns cinco capítulos, como se vê pela Táboa, e pelo confronto com outros livros de caça», y de Krus («Livro de Falcoaria», art. cit., pp. 408-409), que señala que esta obra carece de «os últimos dois capítulos». Contabilizando los capítulos que figuran en el índice inicial, Andrade señala que la obra consta de 23, pero en realidad serían 24 los capítulos que la forman, pues en el desarrollo del texto se introduce uno del que no da cuenta el índice: entre los que corresponderían al XIV (Capitollo da perna quebrada) y XV (Capitollo do Jnchaço do uentre que chamom Jtropego) de la Tauoa, se integra un capítulo que no figura en ella y que pasa a ser consecuentemente el Xv, «Capitollo $x^{\circ}$ da aa quebrada da aue segundo que ey dicto no capitollo dante deste em razom dos cajooes per que magneira aveem aas aues» (fol. 58v, lín. 1-2). 
formado por 31 capítulos. Sobre las relaciones entre la obra de Mendanha y el texto de Menino del CÓD. 2294 el hispanista sueco se manifiesta en los siguientes términos:

los capítulos 5-26 [de la obra de Mendanha] no son más que copias de los capítulos 1-21 de Menino. [...] Los capítulos que copió Mendanha de la obra de Menino están sacados del manuscrito $B$ [el CÓD. 2294 de la BNP], con el que concuerdan siempre. [...] El manuscrito $B$ está mutilado, terminando abruptamente en medio del capítulo 18 [...]. El texto de Mendanha lleva el fin del capítulo 18 y además los capítulos 19, 20 y 21; pero como termina en medio del capítulo $21[\ldots]$, es de presumir que ya en el tiempo en que Mendanha lo copiaba, el manuscrito $B$ estaba mutilado, aunque menos que hoy día, faltándole menos páginas que ahora ${ }^{39}$.

\section{MISE EN PAGE Y MISE EN TEXTE}

Como bien se constata en el catálogo en línea de la BNP, el ejemplar fue «aparado, afectando notas marginais». En efecto, con el objeto de igualar los márgenes externos de los folios, estos fueron recortados hasta adquirir unas dimensiones aproximadas de $270 \mathrm{x}$ $195 \mathrm{~mm}$. En cuanto a la mise en page, se observa la existencia de perforaciones que trazan la caja de justificación y delimitan un espacio de la página destinado a la escritura de aproximadamente $190 \mathrm{x}$ $130 \mathrm{~mm}$. con líneas de justificación que parecen ejecutadas a punta seca, si bien se advierten puntualmente posibles trazas de mina que quizá solo sean el producto del arrastre de la punta seca a través del papel (cfr., p. ej., fol. 38r, 49r, 49v, 51v, 53v). En el área de escritura, el copista, en letra gótica cursiva redonda y con tinta negra, reproduce el texto a página completa sin líneas rectrices, lo que determina que el tamaño de la letra sea desigual y que el número de líneas sea variable: dejando a un lado aquellos folios en los que hay espacios en blanco entre el título del capítulo y el inicio de su exposición según una disposición del contenido en el manuscrito que no es uniforme, se observa que el número de líneas oscila entre las 26 (fol. $28 \mathrm{v}$ ) y las 34 (fol. 2 r).

${ }^{39}$ Gunnar Tilander, «Acerca del Livro de Falcoaria de Pero Menino», Revista de Filología Española, 23/3 (1936), pp. 255-274, p. 259. Vid. también Fradejas Rueda, «Aproximación a la literatura», art. cit., pp. 213-214. Al no haber consultado la obra de Mendanha (que permanece inédita) ni el ms. Sloane (para cuyo contenido cfr. ibid., p. 257 y Rodrigues Lapa, Livro de Falcoaria, ed. cit., pp. 1x-lxvii), no es posible corroborar la hipótesis de Tilander. Aunque las cosas podrían ser como este relata, también podría haberse dado el caso de que, de ser ciertas las analogías señaladas, Mendanha no hubiese redactado su obra a partir del COD. 2294 en un momento en que estaba menos mutilado que en la actualidad, sino que el modelo fuese otro manuscrito que, también mutilado, transmitía una versión de Pero Menino afín a la de aquel, derivando ambos, pues, de un antecedente común. 
La caja de escritura está delimitada por amplios márgenes que fueron aprovechados en épocas diferentes $-\mathrm{y}$, por lo tanto, por manos diferentes- para la reproducción de notas de tipología variada cuya lectura se ve obstaculizada en no pocos casos por la difícil interpretación de esas manos y por el referido trabajo de igualación de los folios del volumen. Señala la ficha del catálogo en línea del manuscrito que en él hay «notas marginais da época e posteriores, estas últimas com uma receita (f. 1, 14) e uma oração (f. 43 v. e 44)». Al respecto de estas, Pereira apunta que las anotaciones de los márgenes inferiores de los fols. $1 \mathrm{r}, 43 \mathrm{v}$ (44v de la numeración moderna) y $44 \mathrm{r}$ (es decir, 45r) son del siglo $\mathrm{Xv}^{40}$ y que la receta del margen inferior del fol. $14 \mathrm{r}$ está también «em letra contemporanea» ${ }^{41}$, aunque la mano parece diferente. El conjunto de información paratextual que aparece en el manuscrito se completa con anotaciones diversas que van referidas, sobre todo, al $L A$. Por un lado, en los márgenes laterales de ciertos folios $(2 \mathrm{r}, 5 \mathrm{r}, 6 \mathrm{v}, 7 \mathrm{r}, 8 \mathrm{v}, 9 \mathrm{r}$, etc.) hay notas que refieren aspectos estructurales del texto o de su contenido y que, según apunta el bibliotecario portugués para la del fol. $5 \mathrm{r}$, tienen «letra do sec. XV cursiva $\rangle^{42}$. Por otro lado, en los cuatro primeros fols. hay marginalia que podrían describirse como glosas semánticas de ciertas voces del $L A$ destacadas en el texto con trazos horizontales de mayor o menor longitud por la parte superior y/o inferior y con un pequeño signo en forma de cuña a la izquierda (y a veces también a la derecha); para la única nota de este tipo reproducida por Pereira, el estudioso señala que está escrita «em letra do fim ou meado do séc. XVI» ${ }^{43}$. Por último, a partir del fol. 33r, en los márgenes de algunos folios una mano diferente, de cuya existencia no da cuenta Pereira, escribe notas que parecen reproducir algunos vocablos del texto ${ }^{44}$.

${ }^{40}$ Pereira, «Livro d'Alveitaria», ed. cit., p. 2 , n. 1 y p. 60, n. 2

${ }^{41}$ Ibid., p. 22, n. 1.

${ }^{42}$ Ibid., p. 8, n. 1. La nota en cuestión dice «nom menos de dous» y va referida a la información hipológica del texto de que «o cauallo nunca deue de seer tomado nem preso ante de dous anos / Ca prendendoo ou o metendo e $m$ soltas em quanto ffor majs nouo reçeberja per hy majs aginha dapno per que veerja a mancar» (fol. 5r, lín. 8-11), demarcada por un trazo vertical, a la derecha del cual se escribe la apostilla. A juzgar por el color rojo de la tinta con que se escribe una de estas notas, «[a]charas os †...†aaes dos ca[uall]os» (fol. 9v), podría argumentarse que son responsabilidad de quien trazó los calderones rojos y el relleno de algunas letras del texto en ese color (cfr. infra).

${ }^{43}$ Ibid., p. 6, n. 1. Se trata del apunte «esponias» del margen derecho del fol. $3 \mathrm{v}$ dirigido al sustantivo esponlhas del texto (fol. $3 \mathrm{v}, 1.10$ ).

${ }^{44}$ En el fol. 33r aparecen las dos primeras apostillas de esta mano: en el margen superior se reproduce el sintagma «sobrelo giolho» que aparecía al final del fol. precedente, «Huũa Jnfirmjdade se faz sobrelo giolho do cauallo» (fol. 32v, lín. 25-26); en el margen derecho se repite la frase preposicional «so o geolho» del enunciado «Ffazesse hũa Jnfirmjdade aos cauallos so o geolho da parte de dentro» (fol. 33r, lín. 12-13). Da noticia, en cambio, Pereira de un indescifrable comentario, de letra diferente de las anteriores, que figura en el fol. $24 \mathrm{r}$ en sentido contrario al de la escritura y que el estudioso reproduce del siguiente modo: «Vejo se aho domingo a hua ora do dia 29 de outubro tres dias por andar do dia de todolos santos de 1600 anos e segundou bespora da bespora de natal as 11 oras do qual prosedeo o custumado» (Pereira, «Livro d'Alveitaria», ed. cit., p. 35, n. 1). 
Por lo que atañe a la mise en texte, sin pretensión de constatar más que tendencias que cuentan con excepciones, en la reproducción del $L A$ no se advierte por parte del amanuense un especial cuidado en la estratificación de la materia. Si algunos elementos de su macroestructura (título, prólogo, índice) están destacados, otros, como el explicit, no están "tipográficamente" individualizados. Por lo que se refiere a la organización del contenido de los capítulos, se advierte una tendencia a iniciar la escritura de los epígrafes que anuncian cada capítulo en la misma línea en la que concluye el capítulo precedente; la redacción de dicho epígrafe en una línea independiente solo se convierte en constante a partir del capítulo 41 de la segunda parte. En cambio, el comienzo de la exposición de cada uno de los capítulos tiende a destacarse separándolo del epígrafe que lo anuncia -aunque no siempre- y utilizando una capital que, de tamaño desigual, es normalmente de mayores proporciones y en ocasiones, como la del mismo prólogo, puede abarcar varias líneas de escritura. En la disposición de la materia de cada capítulo no se advierte ningún cuidado especial por parte del amanuense y esta circunstancia es particularmente notoria en los capítulos de la segunda parte: con una microestructura regular que describe en primer lugar cada enfermedad del caballo y refiere después las medicinas para su curación, el paso de la sección etiológica a la terapéutica - del que textualmente da cuenta la fórmula «a cura desta doença he tall» y otras análogas-, no es destacado de modo alguno en la reproducción del texto, escribiéndose una sección a continuación de la otra.

Para jerarquizar el contenido de los capítulos del $L A$ el amanuense traza algunos - pocos- calderones y ciertos signos de puntuación, generalmente un punto y dos barras .// (en menos casos, un punto y una barra ./), por lo común seguido de mayúscula ${ }^{45}$. Guiándose por estas sencillas marcas del copista, las mayúsculas con las que se iniciaba la palabra que las seguía fueron rellenadas con color rojo, siendo tan contados los casos en que tal circunstancia no se da que las excepciones pasan desapercibidas. Dicha técnica se utiliza también para destacar la mayúscula inicial de los epígrafes y las capitales de mayores proporciones con las que se marca el comienzo de la exposición de cada capítulo. El uso de la tinta roja se extiende también al diseño de calderones - «formados por dois traços rectilíneos traçados em ângulo recto, como uma gama maiúscula grega», según la caracterización de la ficha del catálogo en línea de la BNP- en los epígrafes que presentan los capítulos, en el inicio del desarrollo de los capítulos, en la señalización de algunos item de ciertos capítulos y en la individualización del explicit, cuya especificidad habría

${ }^{45}$ Aunque estas marcas contribuyen a aislar los parágrafos en que desglosa la materia de cada capítulo, también poseen un valor sintáctico, pues en ocasiones ayudan a individualizar ciertas subordinadas (sobre todo las iniciadas con la partícula $c a$, pero también otras como porque, pero) o a identificar los elementos de una enumeración. 
pasado desapercibida al escribirse en la misma línea en la que acaba el último capítulo del texto y con minúscula inicial ${ }^{46}$.

El empleo de marcas, mayúsculas y distintos tipos de tinta da lugar a una señalización múltiple $-\mathrm{y}$, si se quiere, redundante- de la estructura de la obra. Podría aventurarse que detrás de la utilización de la tinta de color rojo podría estar una persona distinta del copista, pues quien trazó en ese color los calderones y rellenó las mayúsculas con el fin de contribuir a la estructuración de los capítulos y señalar los cambios de contenido en el desarrollo de los mismos, guiado por los signos diseñados por el copista, llega incluso a ocultarlos ${ }^{47}$. Sugestiva hipótesis que carece, no obstante, de datos que la sustenten sería pensar que quien, utilizando la tinta roja, volvió sobre una estructura ya destacada con distintas marcas por el copista, lo habría hecho o bien porque estaba cotejando el códice con otro donde el contenido sí estaba estratificado o bien porque estaba pensando en preparar el manuscrito para la elaboración de una copia que o no llegó a ejecutarse o se ha perdido.

Recibido: $14 / 12 / 2017$

Aceptado: 7/02/2018

${ }^{46}$ Sobre los procedimientos utilizados para organizar y jerarquizar el contenido de los textos en los códices medievales, la finalidad didáctica de los mismos y las funciones demarcativas de los colores, vid. Inés Fernández-Ordóñez, «Ordinatio y compilatio en la prosa de Alfonso el Sabio», en Mónica Castillo Lluch y Marta López Izquierdo (eds.), Modelos latinos en la Castilla medieval, Madrid-Frankfurt am M., Iberoamericana-Vervuert, 2010, pp. 239270; Ead., «Los colores y la triple articulación textual en los códices de Alfonso X el Sabio», en Isabel de Barros Dias y Carlos F. Clamote Carreto (eds.), Cores. Actas do VII Colóquio da Secção Portuguesa da Associação Hispânica de Literatura Medieval, Lisboa, Universidade Aberta, 2010, pp. 37-46 y pp. 343-346.

${ }^{47}$ Diferente se muestra la mise en texte para la Falcoaria de Menino, pues los calderones y el relleno de las letras que siguen al punto y la(s) barra(s) son siempre en tinta roja, pero después de esas marcas no se trazan calderones que las anulen. El uso de los calderones en ese otro texto se reserva, en efecto, para señalar exclusivamente los epígrafes que presentan los capítulos a partir del tercero. Desde este hasta el último, su individualidad estaba ya destacada al estar precedida y seguida por espacios en blanco, frente a lo que sucede con los dos primeros capítulos de la obra, para los que el desarrollo del contenido se escribe a continuación del epígrafe. 
$\cos$

\author{
EL LIVRO DE ALVEITARIA DEL CÓD. 2294 \\ DE LA BIBLIOTECA NACIONAL DE PORTUGAL: \\ ANOTACIONES PARA SU HISTORIA Y DESCRIPCIÓN
}

RESUMEN: A partir de los primeros catálogos, de finales del siglo XVIII, de la Biblioteca Nacional de Portugal, este artículo profundiza en la identificación del CÓD. 2294 con el Livro de alveitaria donado por Cenáculo en la etapa fundacional de la institución y con el manuscrito catalogado inicialmente como H-5-39. Tomando en consideración aquellos (y otros) documentos, así como las primeras descripciones del ejemplar (en particular, las de Francisco Martins de Andrade, en la segunda mitad del siglo XIX, y Gabriel Pereira, a comienzos del siglo Xx), se revisan y matizan datos relativos a su contenido, a su cronología y a su materialidad con el propósito de subsanar algunas incorrecciones y proporcionar datos que contribuyan a ofrecer una más precisa caracterización del manuscrito.

Palabras Clave: BNP CÓD. 2294, codicología, Manuel do Cenáculo, Mestre Giraldo

\title{
THE LIVRO DE ALVEITARIA OF COD. 2294 \\ FROM THE NATIONAL LIBRARY OF PORTUGAL: NOTES FOR ITS HISTORY AND DESCRIPTION
}

\begin{abstract}
Based on the earliest catalogues, dating from the late eighteenth century, in the National Library of Portugal, this essay delves into the identification of COD. 2294 with the Livro de alveitaria donated by Cenáculo at the foundational stage of this institution, and with the manuscript originally classified as H-5-39. Taking into account these (among other) documents, as well as the earliest descriptions of this volume (mainly those by Francisco Martins de Andrade in the second half of the nineteenth century, and by Gabriel Pereira at the beginning of the twentieth century), this paper analyses and explains several details concerning its contents, its chronology and its material aspect in order to correct mistakes and provide further data that may contribute to a more precise rendering of the manuscript.
\end{abstract}

KeYwords: BNP COD. 2294, codicology, Manuel do Cenáculo, Mestre Giraldo. 